\title{
Условия кристаллизации мафических включений и пород собского комплекса (Полярный Урал)
}

\author{
Шуйский А.С., Удоратина О.В. \\ Институт геологии Коми НЦРАН, Сыктывкар, self88@yandex.ru
}

\begin{abstract}
Аннотация. В статье приведены результаты расчетов температуры и давления на основе химического состава породообразующих минералов амфибола и плагиоклаза пород собского комплекса и мафических включений. Использованы микрозондовые анализы и целый ряд геобарометров и геотермометров. В результате проведенных исследований установлено, что породы комплекса имеют близкие интервалы температур (и давления) кристаллизации, именно поэтому процессы ассимиляции наблюдаются достаточно редко.

Ключевые слова: мафические включения, температуры кристаллизации, геотермометры, геобарометры, Полярный Урал.
\end{abstract}

\section{Crystallization conditions of mafic inclusions and rocks of the Sobsky complex (Polar Urals)}

\author{
Shuysky A.S., Udoratina O.V. \\ Institute of Geology Komi SC UB RAS, Syktyvkar, self88@yandex.ru
}

\begin{abstract}
The article reviews results of calculations of temperatures and pressures on the basis of the chemical composition of rock-forming minerals of amphibole and plagioclase of the Sobsky complex and mafic inclusions. We have used microprobe analyzes and a number of geobarometers and geothermometers. We have established that the rocks of the complex had similar ranges of temperature (and pressure) of crystallization, therefore assimilation processes are rarely observed.
\end{abstract}

Keywords: mafic inclusions, crystallization temperatures, geothermometers, geobarometers, Polar Ural.

\section{Введение}

Первично магматические мафические (меланократовые) включения (МВ) имеют проблематичный генезис и встречаются в породах различного состава. На Полярном Урале мафические включения формируют типичный облик плагиогранитоидов собского (Лагортинско-Кокпельского) комплекса, породы которого развиты в Восточно-Уральской (Тагило-Магнитогорской) зоне и представляют собой основание палеоостровной дуги.

Наблюдаемые MB - темные и более тонкозернистые разности, чем вмещающие их породы комплекса, они отчетливо выделяются на общем фоне скальных выходов благодаря цвету и своей мелкозернистости. Также они хорошо сохраняются на выветрелых поверхностях, формируя положительные выпуклые формы. Форма МВ разнообразна, но чаще встречаются округлые, эллипсовидные образования, также наблюдаются и угловатые и амебообразные (бесформенные). Размеры включений чаще всего от 10 до 30 (50) см, но отмечаются как более крупные, так и более мелкие. Важной характеристикой являются контакты MB с вмещающими породами: чаще всего они четкие, резкие, однако в единичных случаях отмечены близкие по облику более тонкозернистые каймы. МВ с размытыми нечеткими и нерезкими границами встречаются реже, еще реже отмечаются гибридные по своему происхождению породы, формирующиеся на контакте МВ и вмещающих их пород собского комплекса.

Отсутствие или присутствие признаков ассимиляции породами комплекса МВ, зависит от длительности пребывания МВ в кристаллизующемся расплаве, температуры кристаллизации МВ и температуры кристаллизации пород комплекса.

Нами на основе микрозондовых анализов породообразующих минералов (полученных в «Геонаука», г. Сыктывкар) с использованием расчета по различным геобарометрам и геотермометрам рассчитаны $\mathrm{P}-\mathrm{T}$ условия формирования МВ и пород комплекса. 


\section{Результаты исследований}

Породы комплекса (опробованные в контакте с MB) варьируют в широком интервале составов: габбро-диорит - диорит - кварцевый диорит - гранодиорит - тоналит - плагиогранит. Для пород МВ интервал вариаций более узкий: габбро - габбро-диорит - диорит. При этом в каждой опробованной паре составы МВ и вмещающих пород широко варьируют (рис. 1).

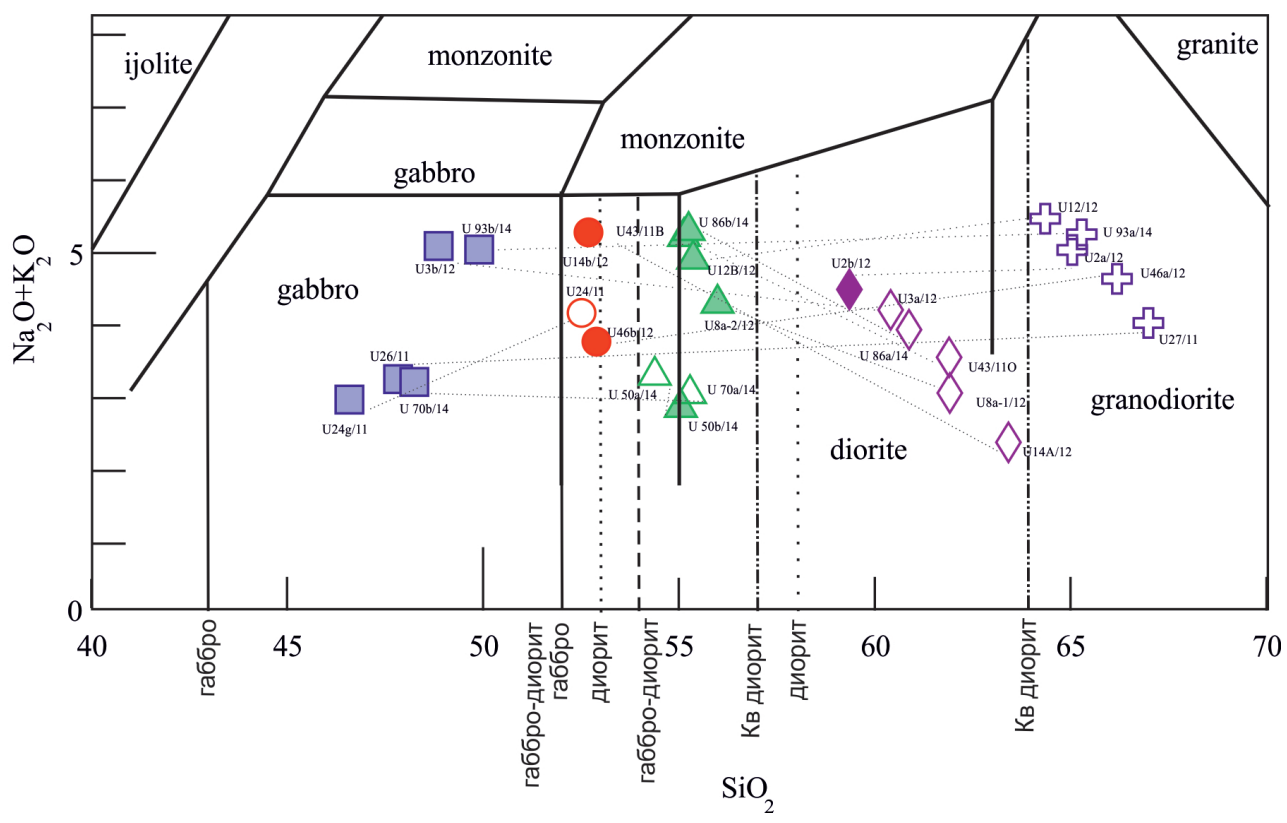

Рис. 1. Положение точек составов изученных MB и пород комплекса на диаграмме TAS.

Стрелками указаны опробованные пары - MB и на контакте породы комплекса. Условные обозначения, квадрат - габбро, кружок - габбро-диориты, треугольник - диориты, ромб - кварцевые диориты, крестик - тоналиты. Закрашенные значки - MB, незакрашенные - породы комплекса.

Fig. 1. Location of composition points of studied ME and rocks of the complex in the TAS diagram. The arrows indicate tested pairs - MI and on the contact of the rocks of the complex. Legend: square - gabbro, circle - gabbro-diorites, triangle - diorites, rhombus - quartz diorites, cross - tonalites. Shaded icons - ME, uncolored rocks of the complex.

И породы комплекса и породы МВ имеют близкий петрографический состав, тем не менее, MB всегда имеют более основной состав по отношению к вмещающей его породе.

Состав пород собского комплекса варьирует в рамках габбро-габбродиорит-диорит-кварцевый диорит-тоналит-плагиогранит. Цвет породы варьирует от темно-серого до бело-серого (CI - 30 (редко 50 в габбро имеющих локальное распространение)). Средне- и крупнозернистые, порфировидные, массивные. Под микроскопом наблюдаются гипидиоморфнозернистые микроструктуры. Вкрапленники плагиоклаза $\left(\operatorname{An}\left({ }_{72-0}\right)\right)$, амфибола $(\mathrm{Mg}$-роговая обманка), ( \pm биотит) погружены в матрикс такого же минерального состава, отмечается кварц и калиевый полевой шпат. Акцессорные минералы - апатит, титанит; рудные - магнетит, титаномагнетит; вторичные - эпидот, хлорит.

Состав пород МВ варьирует в пределах габбро-габбродиорит-диорит. Цвет породы от черного, темно-серого до серого (CI -50-70). Петрографический состав близок вмещающим породам комплекса: порфировидные вкрапленники плагиоклаза (более раннего $\left.\operatorname{An}\left({ }_{77-20}\right)\right), \mathrm{Mg}$-амфибола, ( \pm биотит) погружены в основную массу сложенную теми же минералами. Акцессорные минералы - апатит, титанит; вторичные - эпидот, хлорит; рудные - магнетит, титаномагнетит, пирит. На микроуровне включения при общей схожести отличаются микроструктурами и более основным составом породообразующих минералов.

Согласно данным микрозондового анализа вариации составов плагиоклазов вкрапленников (в центре и в краевой части), а также основной массы по составу отличаются. Как видно на графиках 

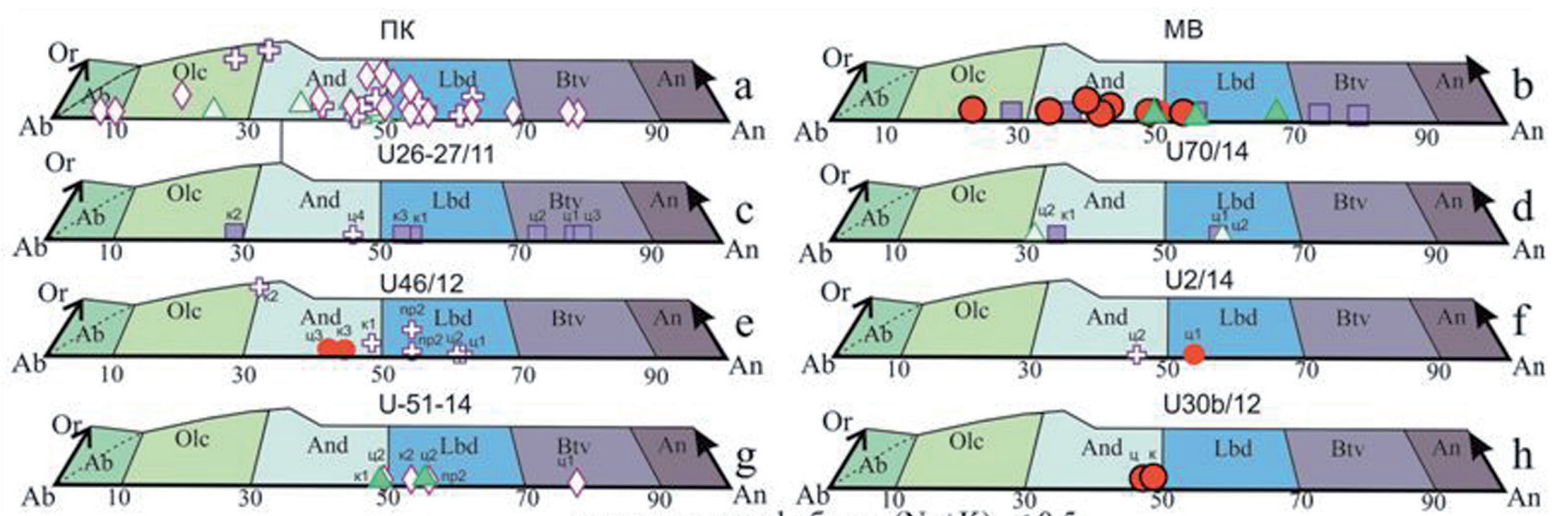

$\mathrm{U} 3 \mathrm{bb} / 12$

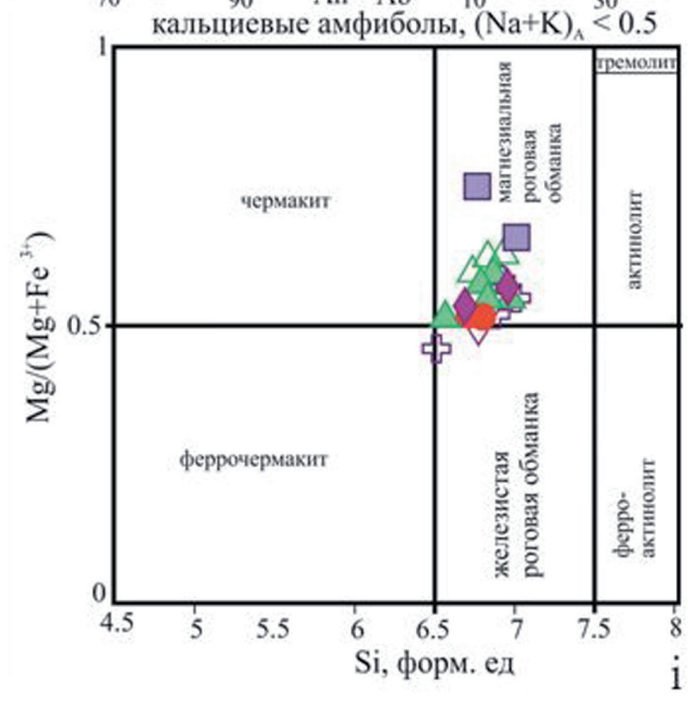

Рис. 2. Диаграмма деление плагиоклазов и щелочных полевых шпатов (высокотемпературная неупорядоченная серия) (a-h). Сокращения: Ab - альбит, An - анортит, Or - ортоклаз, And - андезин, Anor - aнортоклаз, Btv -- битовнит, Olc - олигоклаз, Lbd - лабрадор, Snd - санидин. (Deer et al., 1963) и бинарная диаграмма MМА для классификации Са амфиболов (а). Са[В]>=1.50 (Leake et al., 1997-2004). Условные обозначения см. рис. 1.

Fig.2. Diagram division of plagioclase and alkaline feldspars (high-temperature disordered series) (a-h). Abbreviations: Ab - albite, An - anortite, Or - orthoclase, And - andesine, Anor - anorthoclase, Btv - bitovnite, Olc - oligoclase, Lbd - Labrador, Snd - sanidine. (Deer et al., 1963) and binary MMA diagram for classifying Ca amphiboles (i). $\mathrm{Ca}[\mathrm{B}]>=1.50$ (Leake et al., 1997-2004). Conventions are in Fig. 1.

(рис. 2, a-h), точки составов плагиоклазов значительно перекрываются, но в целом для пород МВ характерен более основной (более Са) плагиоклаз.

Амфибол МВ представлен Mg-роговой обманкой (рис. 2 i), слюда - биотитом, магнезиальность амфибола выше в МВ, чем в породах собского комплекса. Состав минералов приведен в работах (Горбаченко и др., 2015, 2016).

Порфировидный облик пород комплекса и МВ свидетельствует о гипабиссальных условиях их кристаллизации, присутствие роговой обманки, биотита указывает на водонасыщенный флюидный режим кристаллизации пород.

На диаграмме TAS фигуративные точки составов MB и вмещающих их пород собского комплекса занимают одни поля, со смещением в более основную область. Породы принадлежат к известково-щелочной серии, имеют натриевый тип щелочности. На геохимических диаграммах формы спектров распределения РЗЭ близки, на мультиэлементых наблюдается обогащение крупноионными литофильными элементами относительно высокозарядных элементов, с проявленными положительными аномалиями по $\mathrm{Cs}, \mathrm{Ba}, \mathrm{K}, \mathrm{Pb}, \mathrm{Sr}, \mathrm{Nd}, \mathrm{Sm}$, Dy и отрицательными - по Rb, Nb, Zr, P, Ti, что подтверждает их надсубдукционную природу. 
Изучение химических составов пород комплекса, контактирующих с МВ, показывает, что вблизи МВ породы комплекса имеют более основной состав, так как основной объем комплекса сложен тоналитами.

Рассчитанные температуры и давления приведены в табл. 1. Наиболее реальные средние температуры получены при помощи геотермометра (Ridolfi et al., 2010), в табл. 1, колонка 10. Согласно расчетам, средние температуры: $\mathrm{MB}$ габбро $\left(810^{\circ} \mathrm{C}\right)$, габбро-диориты $\left(813^{\circ} \mathrm{C}\right)$, диориты $\left(798^{\circ} \mathrm{C}\right)$, кварцевые диориты $\left(778^{\circ} \mathrm{C}\right)$. Породы комплекса вблизи $\mathrm{MB}$ : диориты $\left(804^{\circ} \mathrm{C}\right)$, кварцевые диориты $\left(817^{\circ} \mathrm{C}\right)$, тоналиты $\left(769^{\circ} \mathrm{C}\right)$.

Полученные с помощью различных геобарометров давления приведены также в табл. 1, мы ориентируемся на колонку 4. Давление: МВ габбро (1.5Kbar), габбро-диориты (1.8Kbar), диориты (1.4Kbar), кварцевые диориты (1.3Kbar). Породы комплекса вблизи МВ: диориты (1.3Kbar), кварцевые диориты (1.7Kbar), тоналиты (1.2 Kbar).

Соответственно, глубины формирования варьируются для мафических включений от 4.6 до 6.3 км, а пород комплекса от 4.3 до 6.2 км.

Содержания воды в расплаве, равновесном с роговой обманкой, оценивается в породах комплекса 6-7 мас. \%, а в МВ 7-8 мас. \%.

Таблица 1. Расчетные температуры и давления пород комплекса и МВ.

Table 2. Calculated temperatures and pressures of the rocks of the complex and ME.

\begin{tabular}{|c|c|c|c|c|c|c|c|c|c|c|c|c|}
\hline \multirow{2}{*}{ Обр. } & \multirow{2}{*}{ Название породы } & \multirow{2}{*}{ № обр. } & $\mathrm{P}[1]$ & $\mathrm{P}[2]$ & Pcp & $\mathrm{P}[3]$ & $\mathrm{T}[4]$ & $\mathrm{T}[5]$ & $\mathrm{T}[6]$ & $\mathrm{T}[7]$ & Tcp & $\mathrm{T}[8]$ \\
\hline & & & 1 & 2 & 3 & 4 & 5 & 6 & 7 & 8 & 9 & 10 \\
\hline ПК & тоналит & $\mathrm{U} 2 \mathrm{a} / 12$ & 5.7 & 5.95 & 5.82 & - & 10.32 & 90.34 & 750.03 & 586.2 & 09.22 & - \\
\hline MB & кв. диорит & U2б/12 & 2.83 & 3.2 & 3.01 & 1.29 & 793.99 & 746.29 & 797.35 & 633.74 & 742.84 & 775 \\
\hline ПК & & $\mathrm{U} 7 \mathrm{a} / 12$ & 3.84 & 4.16 & 4 & 1.74 & 816.97 & 1.51 & 705.08 & 70.18 & 695.94 & 812 \\
\hline MB & 2 & U7б/12 & 3.13 & 3.48 & 3.3 & 1.42 & 768.46 & 719.45 & 729.95 & 591.23 & 702.27 & 787 \\
\hline ПК & кр пиоп & $\mathrm{U} 43 \mathrm{a} / 12$ & 4.35 & 4.66 & 4.5 & - & 805.94 & 619.76 & 637.29 & 520.4 & 645.84 & 823 \\
\hline MB & & & 4.63 & 4.92 & 4.77 & - & 745.72 & 42.76 & 678.65 & 549.99 & 654.28 & 821 \\
\hline ПК & - & 12 & 2.51 & 2.89 & 2.7 & 1.19 & 739.57 & 763.11 & 886.61 & 686.76 & 769.01 & 758 \\
\hline MB & & $126 / 12$ & 5.28 & 5.55 & 5.42 & - & 752.53 & 638.97 & 631.05 & 517.77 & 635.08 & 844 \\
\hline ПК & & & 2.57 & 2.95 & 2.76 & 1.20 & 780.42 & 745.54 & 794.04 & 632.92 & 738.23 & 795 \\
\hline MB & габбр & 14 & 3.1 & 3.46 & 3.28 & 1.42 & 738.38 & 641.25 & 621.12 & 518.34 & 629.77 & 807 \\
\hline ПК & & & 2.55 & 2.93 & 2.7 & 1.21 & 740.78 & 694.12 & 677.96 & 548.72 & 665.4 & 777 \\
\hline ПК & & 11 & 2.7 & 3.07 & 2.89 & 1.25 & 759.22 & 745.66 & 705.15 & 579.98 & 697.5 & 817 \\
\hline ПК & & $/ 14$ & 2.81 & 3.17 & 2.99 & 1.29 & 805.58 & 757.51 & 764.81 & 614.1 & 735.5 & 802 \\
\hline MB & Кв. & 14 & 2.67 & 3.05 & 2.86 & - & 750.8 & 675.4 & 670.72 & 551.8 & 662.18 & - \\
\hline MB & кв. Д & & 4.39 & 4.7 & 4.55 & - & 791.72 & 668.32 & 661.91 & 537.14 & 664.77 & - \\
\hline MB & & & 3.07 & 3.42 & 3.24 & 1.40 & 752.86 & 691.89 & 661.59 & 545.83 & 663.04 & 807 \\
\hline MB & диою & $/ 12$ & 2.95 & 3.31 & 3.13 & 1.35 & 728.72 & 654.08 & 669.98 & 553 & 651.45 & 793 \\
\hline MB & & & 2.76 & 3.13 & 2.95 & 1.28 & 688.68 & 552.63 & 563.8 & 483.13 & 572.06 & 778 \\
\hline MB & sin & $51 / 14$ & 2.97 & 3.33 & 3.15 & 1.35 & 795.41 & & 796.39 & 633.35 & 742.61 & 784 \\
\hline MB & & $86 / 14$ & 2.84 & 3.21 & 3.03 & 1.31 & 734.05 & 668.07 & 695.19 & 568.56 & 666.47 & 781 \\
\hline MB & & & 4.33 & 4.64 & 4.49 & - & 733.93 & 657.99 & 698.07 & 565.23 & 663.81 & 811 \\
\hline MB & габбро-диорит & U30б/12 & 3.91 & 4.24 & 4.07 & 1.77 & 777.49 & 729.94 & 750.16 & 599.21 & 714.2 & 808 \\
\hline $\mathrm{MB}$ & габбро & $\mathrm{U} 26 / 11$ & 4.26 & 4.57 & 4.42 & 1.92 & 775.52 & 787.28 & 982.19 & 732.09 & 819.27 & 841 \\
\hline MB & габбро & U38/12 & 2.39 & 2.77 & 2.58 & 1.15 & 761.7 & 736.26 & 813.08 & 645.19 & 739.06 & 783 \\
\hline
\end{tabular}

Примечание: точность $\mathrm{P}^{[1-2]} \pm 0.5 \mathrm{Kbar}$, точность $\mathrm{T}^{[3]} \pm 75^{\circ} \mathrm{C}, \mathrm{T}^{[8]} \pm 22{ }^{\circ} \mathrm{C}$; ПК - породы комплекса, МВ - мафические включения; $\mathrm{P}^{[1]}$ - (Hammarstrom J. M., Zen E-An, 1986); $\mathrm{P}^{[2]}$ - (Schmidt M.W., 1991); P[3] - (Ridolfi et al., 2010), $\mathrm{T}^{[4]}$ - (Blundy J.D., Holland T.J.B., 1990); $\mathrm{T}^{[5]}$ - (Holland T., Blundy J., 1994); T $\mathrm{T}^{[6]}$ - (Jaques A.L., Blake D.H., Donchak P.J.T., 1982); $\mathrm{T}^{[7]}$ - (Spear F.S., 1981) $\mathrm{T}^{[8]}$ - (Ridolfi et al., 2010). $\mathrm{P}_{\text {ср }}$ рассчитаны из $\mathrm{P}^{[1-2]}, \mathrm{T}_{\text {ср }}$ рассчитаны из $\mathrm{T}^{[4-6]}, \mathrm{T}^{[4-6]}$ рассчитаны с учетом $\mathrm{P}_{\mathrm{cp}}$.

Расчеты показали, что МВ физико-химически и термически соответствуют продуктам процесса введения в кристаллизующуюся магму малого по объему количества вещества, которое могло кристаллизоваться из близкого по составу расплава при более высокой температуре и повышенном давлении. Температура плавления этого вещества выше температуры плавления расплава, и оно не может расплавиться в магме. Тем не менее, наблюдаемые процессы ассимиляции и гибриди- 
зации МВ в породах собского комплекса, не рассматриваемые здесь, являются причиной реакционных взаимодействий пород комплекса с МВ (Горбаченко, Удоратина, 2016, 2017).

Первичная природа этого поступающего в магму вещества МВ проблематична. Это может

быть: 1. материал первых, более основных по составу порций расплава, 2. материал, имеющий кумулятивную природу, 3. материал более поздней порции поступивших в расплав основных пород.

Исследования выполняются в рамках госзадания № ГР АААА-А17-117121270035-0.

\section{Литература}

1. Горбаченко К.Н., Удоратина О.В. Условия кристаллизации гибридных пород собского комплекса (Полярный Урал) // Экспериментальная минералогия, петрология и геохимия. Мат-лы VIII Всеросс. шк. молодых ученых. Сборник материалов. Черноголовка: ИПХФ РАН. 2017. С. 30-32.

2. Горбаченко К.Н., Удоратина О.В., Шевчук С.С. Амфиболы мафических включений и пород собского комплекса (р. Лагорта, Полярный Урал) // VII Всероссийская школа молодых ученых «Экспериментальная минералогия, петрология и геохимия»: Сборник материалов. Черноголовка: ИПХФ РАН. 2016. С. 10-12.

3. Горбаченко К.Н., Удоратина О.В., Шевчук С.С. Плагиоклазы пород и мафических включений собского комплекса (бас. р. Лагорта, Полярный Урал) // Структура, вещество, история литосферы ТиманоСевероуральского сегмента. Мат-лы 24-й научной конференции. Сыктывкар. Геопринт. 2015. С. 44-48.

4. Горбаченко К.Н., Удоратина О.В. Гибридные породы собского комплекса (Собский батолит, Полярный Урал) // Петрология магматических и метаморфических комплексов. Мат-лы VIII всеросс. петрограф. конф. с межд участием. Томск. 2016. С. 77-86.

5. Blundy J.D., Holland T.J.B. Calcic amphibole equilibria and a new amphibole-plagioclase geothermometer. // Contrib. Mineral. and Petrol., 1990. V.104. N. 2. P. 208-224.

6. Hammarstrom J. M., Zen E-An. Aluminium in hornblende: an empirical igneous geobarometer // Amer. Miner., 1986. V. 71. № 11/12. P. 1297-1313.

7. Holland T., Blundy J. Non-ideal interactions in calcic amphiboles and their bearing on amphibole-plagioclase thermometry // Contrib. Mineral. Petrol., 1994. V.116. P. 433-447.

8. JaquesA.L., Blake D.H., Donchak P.J.T. Regional metamorphism in the Selwyn Range area north-west Queensland // BMR Journal of Australian Geology and Geophysics. 1982. V. 7. N. 3. P. 181-196.

9. Leake B.E., Woolley A.R., Arps C.E.S., Birch W.D., Gilbert M.C., Grice J.D., Hawthorne C., Kato A., Kisch H.J., Krivovichev V.G., Linthout K., Laird J., Mandarino J.A., Maresch W.V., Nickel E.H., Rock N.M.S., Schumacher J.C., Smith D.C., Stephenson C.N., Ungaretti L., Whittaker E.J.W., Youzhi G. Nomenclature of amphiboles: report of the Subcommittee on Amphiboles of the International Mineralogical Association, Commission on New Minerals and Mineral Names // Canad. Miner. 1997. V. 35. P. 219-246.

10. Leake B.E., Woolley A.R., Birch W.D., Burke E.A.J., Ferraris G., Grice J.D., Hawthorne F.C., Kisch H.J., Krivovichev V.G., Schumacher J.C., Stephenson N.C.N., Whittaker E.J.W. Nomenclature of amphiboles: additions and revisions to the International Mineralogical Association's amphibole nomenclature // Amer. Miner., 2004. V. 89. P. 883-887.

11. Ridolfi F. Stability and chemical equilibrium of amphibole in calc-alkaline magmas: An overview, new thermobarometric formulations and application to subduction-related volcanoes / F. Ridolfi, A. Renzulli, M. Puerini // Contrib. Mineral. Petrol. 2010. V. 160. P. 45-66.

12. Schmidt M.W. Experimental calibration of the Al-in-hornblende geobarometer at 650 C. 3.5-13.0 kbar // Terra abstracts. 1991. V. 3. N. 1. P. 30.

13. Spear F.S. Amphibole-plagioclase equilibria: a empirical model for the relation albite + tremolite $=$ edenite + quatz // Contrib. Miner. and Petrol. 1981. V. 77. N. 4. P. 355-364. Deer, W.A., R. A. Howie, and J. Zussman (1963) Rock-Forming Minerals V. 4. Longmans, London. 435 pp. 